\title{
(Oral) enoximone in asthma
}

\section{To the Editor:}

The Enoximone in status asthmaticus letter [1] referenced our case series from the Netherlands wherein intravenous enoximone (Perfan, Carinopharm, Germany) reversed status asthmaticus in eight patients [2]. Schulz et al. [1] end their letter with the statement that further research is called for; this correspondence is to indicate that research has been carried out and is still ongoing.

Recently, Sовну et al. [3] confirmed our case series with a successful clinical trial, which was performed in Egypt, using the phosphodiesterase (PDE)-3 inhibitor milrinone. We would like to report we are currently treating 12 children and 51 adults (outpatients) with oral enoximone (Perfan) in addition to standard therapy, in the context of investigational use, in search of effectiveness [4]. Enoximone very swiftly and markedly improved difficult-to-treat asthma, as well as reduced steroid and $\beta_{2}$-agonist drugs in 47 of the adult patients, and in 11 of the 12 children. Enoximone in oral form is used to reduce pulmonary arterial pressure by relaxing vascular smooth muscle and it has been used in paediatric post-operative heart failure since $2005[5,6]$. Our average oral doses are $0.0625-0.125 \mathrm{mg} \cdot \mathrm{kg}^{-1}$, which is $1-6 \mathrm{mg}$ per day for children and 5-15 mg per day for adults; some of them take the drug only two or three times per week. In the Netherlands physicians are allowed to treat their patients with drugs that are not indicated/registered for a particular disease, provided dosage, results and side-effects are closely monitored. We contacted the Dutch Inspection for Health Care and Youth regarding our add-on use of enoximone.

Enoximone is a selective PDE-3 inhibitor; it causes an increase in cyclic adenosine monophosphate (cAMP) and in cyclic guanosine monophosphate (cGMP) in the cell, inhibiting entry of calcium ions, resulting in relaxation and subsequent bronchodilatation. Recently published papers show that enoximone has anti-inflammatory properties due to its effect on pro-inflammatory cytokines and inhibits primary human mast cell degranulation, thus reducing inflammation [7, 8]. It also improves the mucosal barrier function, preventing vascular leakage, causing, in underlying cases, oedema, and is effective in reducing granulocyte-macrophage colony-stimulating factor, interleukin (IL)- 6 and tumour necrosis factor (TNF)- $\alpha$ production of epithelial cell cultures that boost an allergic immune response. Enoximone has been shown to be as effective as an anti-pro-inflammatory (IL-6 and TNF $\alpha$ ) as methylprednisolone and has the extra benefit of a superior haemodynamic response in patients undergoing cardiopulmonary bypass surgery [9]. This observation indicates that we have a potentially very effective anti-asthma drug. Safety studies in the past illustrate that "low-dose" enoximone, $50 \mathrm{mg}$ orally 3 times a day $(\mathrm{n}=1854)$, proved to be "safe" (placebo level) in patients with advanced heart failure [10]; our dosage is 10-30 times less. The drug dosage is based on the lowest effective dose and holds a relatively safe profile.

Enoximone appears to be the first new anti-asthma drug for decades that can be used as a (rescue) medication in all phases of asthma.

We will continue to closely observe our asthmatic patients who (with parents) are highly motivated to continue enoximone add-on therapy because of its immediate and beneficiary effect.

@ERSpublications

PDE-3 inhibitors appear to have a large therapeutic value in asthma treatment; this letter provides some of the insights acquired in recent research https://bit.ly/33D9Dgd

Cite this article as: Beute J. (Oral) enoximone in asthma. ERJ Open Res 2020; 6: 00319-2020 [https://doi.org/10.1183/23120541.00319-2020].

Copyright OERS 2020. This article is open access and distributed under the terms of the Creative Commons Attribution Non-Commercial Licence 4.0. 


\section{Jan Beute}

ZH Rivierenland, Tiel, The Netherlands.

Correspondence: Jan Beute, ZH Rivierenland, President Kennedylaan 1, 4002 WP Tiel, The Netherlands. E-mail: beute.almere@gmail.com

Received: 27 May 2020 | Accepted: 2 June 2020

Conflict of interest: Breakthrough Medical Research b.v., of which J. Beute is one of the managing directors, has a patent WO 2015/160249 and/or PCT/NL2015/050246 pending, and a patent US15/303,871 issued and J. Beute is a shareholder in Beute Medical Flow b.v., which holds a majority interest in Breakthrough Medical Research b.v.

\section{References}

Schulz O, Wiesner O, Welte T, et al. Enoximone in status asthmaticus. ERJ Open Res 2020; 6: 00367-2019.

Beute J. Emergency treatment of status asthmaticus with enoximone. Br J Anaesth 2014; 112: 1105-1108.

Sobhy A, Eldin DMK, Zaki HV. The use of milrinone versus conventional treatment for the management of life-threatening bronchial asthma. Open Anesthesiol J 2019; 13: 12-17.

4 Harari S. Randomised controlled trials and real-life studies: two answers for one question. Eur Respir Rev 2018; 27: 180080.

5 Medicines for Children. Enoximone for pulmonary hypertension. 2018. www.medicinesforchildren.org.uk enoximone-pulmonary-hypertension

6 Furck AK, Bentley S, Bartsota M, et al. Oral enoximone as an alternative to protracted intravenous medication in severe pediatric myocardial failure. Pediatr Cardiol 2016; 37: 1297-1301.

7 Beute J, Ganesh K, Nastiti H, et al. PDE3 inhibition reduces epithelial mast cell numbers in allergic airway inflammation and attenuates degranulation of basophils and mast cells. Front Pharmacol. 2020; 11: 470.

8 Beute J, Lukkes M, Koekoek EP, et al. A pathophysiological role of PDE3 in allergic airway inflammation. JCI Insight 2018; 3: e94888.

9 Santarpino G, Caroleo S, Onorati F, et al. Inflammatory response to cardiopulmonary bypass with enoximone or steroids in patients undergoing myocardial revascularization: a preliminary report study. Int J Clin Pharmacol Ther 2009; 47: 78-88.

10 Metra M, Eichhorn E, Abraham WT, et al. Effects of low-dose oral enoximone administration on mortality, morbidity, and exercise capacity in patients with advanced heart failure: the randomized, double-blind placebo-controlled, parallel group ESSENTIAL trials. Eur Heart J 2009; 30: 3015-3026. 